\title{
USING OF LEAN TOOLS IN REVERSE LOGISTICS (LEANVERSE LOGISTICS?)
}

\author{
Makány Gábor \\ PhD student, Intstitute of Regional Economics and Rural Develeopment \\ Kecskemét College, Faculty of Mechanical Engineering and Automation, \\ Department of Economics and Social Sciences
}

\begin{abstract}
Lots of manufacturer base their process planning on lean principles. A straight way of supply chain could use lean tools efficiently. What about reverse orientation of supply chains? Reverse logistics is one of the most remarkable pivot of reverse way supply chains. To form best and useable practices we may have should use proper lean tools. If it realizable at all...

In my paper I ask for those conditions, elements, parts which are responsible for a well working reverse supply chain based on lean tool using systems. Which are the future effects if we use the proper lean tools? What are the consequences of a reverse supply chain works without lean tools.
\end{abstract}

Keywords: leanverse logistics, reverse supply chain, bottleneck effect, waste management, sustainable waste management.

\section{Introduction:}

All of consumer search for perfect products. So, products have huge challange to match every other consumers demands. To match most of demans products need to be procedure by much principles. By these principles products could match more demands of consumers. Efficient use of these princples is much harder than we thought.

Straight way of supply chains are ruled and determined. A manufacturer create product from different materials, components, parts by adding extra work and knowledge. Product heads to the next step. It might be different ways. Products could be reshared by retailers or distributors to consumers or customers.

The logistics activities are the base chain links between the main components. We couldn't exist without these activities. Supply chain components could not communicate orconnect each others without logistics activities. To make a complete supply chain we need to handle one more components. Recycing is the last part of the chain but the promising to develop in (Pónusz, 2013).

According to the first graphic, recycling able to connect to consumers and suppliers. By several logistics activities recycling should connect to other elements of supply chains to prove its reliability. 


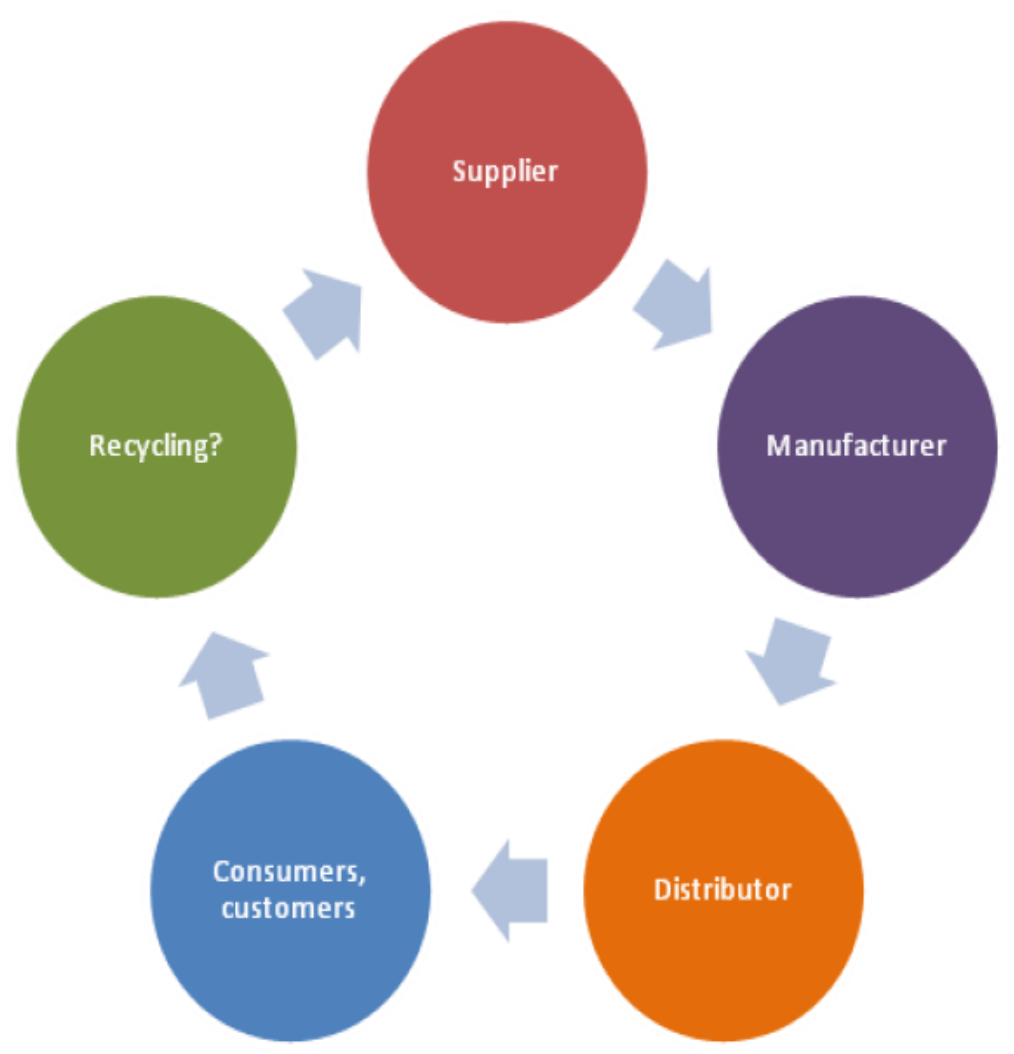

source: made by own

Fig. 1. : Straight way of Supply chains

\section{Methods}

In my opinion the recycling element of supply chain not the best way to express itself. If there are some of customers who deal with the sustainable waste management that doesn't mean they do recycling. The better erxpressions we could pick from hierarchy of waste management. It's been presened on the second graph.

So, there are much more way to get connect between consumers and suppliers. There are reuse, recyle and recover. In my opinion these are the three option where reverse logistics activities could help the improvements of supply chain. Both ends of pyramid are too extreme for logistics.

There is a hard way to reduce the sources which are used for consumer products. It is not a goal for logistics area. We should start this think way earlier. And it is too philosophycal. We are living a society which is mostly based on consumption. There are nothing to do against it. We have to live with this fact. We need to accept that variation of logistics acativities can not reduce the mount of consumpt. 


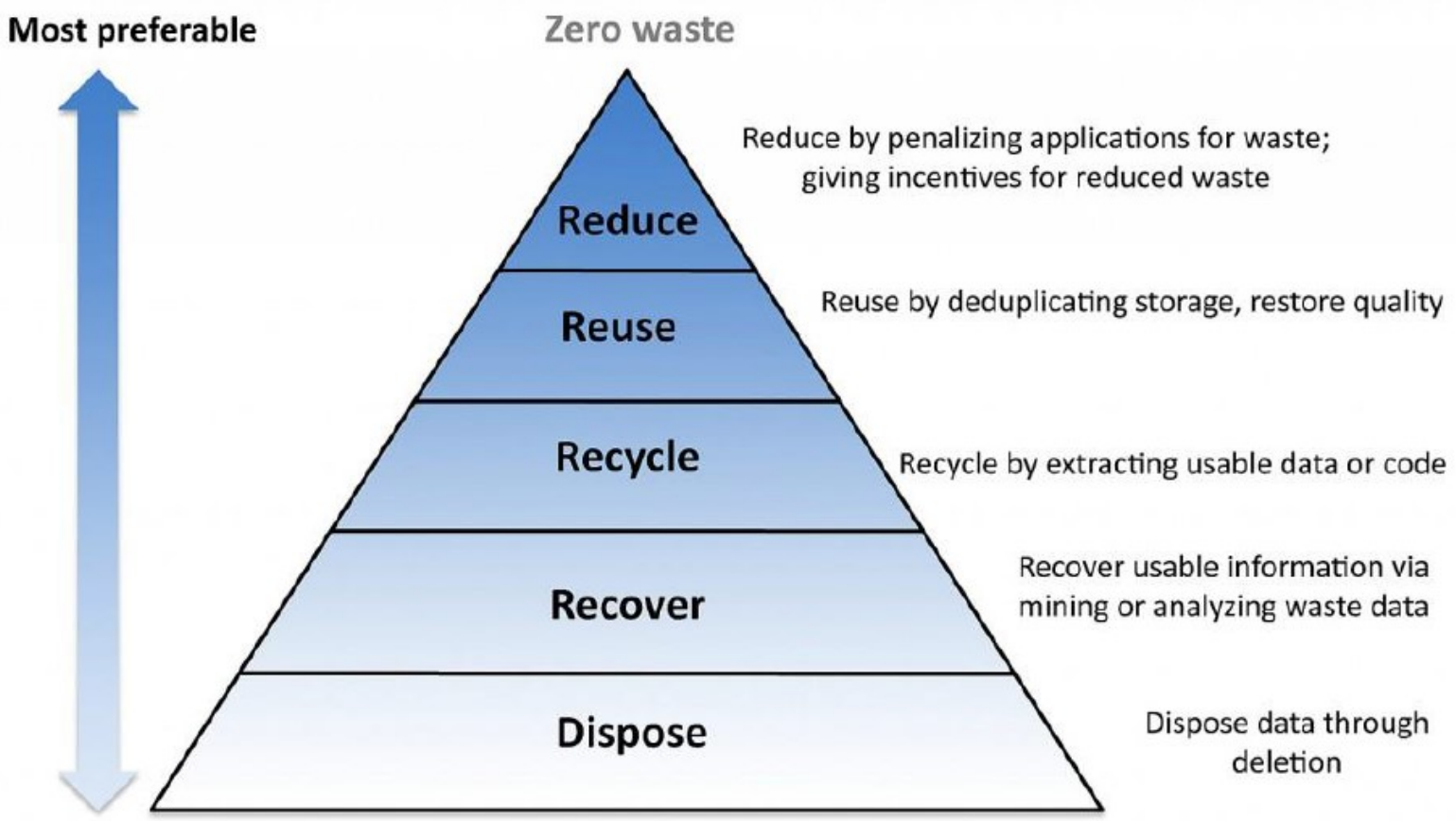

Least preferable

Physical elimination

Fig. 2. : Pyramid of waste management

Source: $\quad$ http://releases.jhu.edu/wp-content/uploads/2011/09/pyramid-royce-low-res1024x629.jpg downloaded: april 15., 2015. search engine: google.com, keywords: waste management

The other end of pyramid is the disposition. It is the least preferable option to treat a used product. It is just a last option. There are kinds of materials which contains that kinf of materials, components which could threat the environment. These products contains dangerous or hazardious substances like below (RoHS Directive 2002/95/EC): lead, mercury, cadmium, hexavalent chromium, polybrominated biphenyl, polybrominated diphenyl ether.

One of the options remove hazardious substances and prepare products to reuse or recycling. If it even possible. The other option split the substances then we just need to dispose those which was infected or contamined. At these options logistics activities can only support not to change the way those work or make huge attraction on them. These may could be like: transporting, forwarding, collecting, commissioning, storaging.

Logistics services at these case could only work as a slave function. I have this opinion because the logistics services just an adaptive area not the determinative one. We use sources and create waste and logistics services just a follower. It can not become a master or leader factor.

At the case of reuse, recycle or recover logistics services could appear in another role. First of all there is lot of way to use logistics services to change the awarding of reuse, recycle and recover. Rest of my paper I mean reuse, recycle, recover as one unit and I call them RRR ways. The RRR ways are the main areas where logistics activities need to focus on. What kind of logistics services we can talk about: collecting, separating, forwarding.

These logistics services can get more influences on RRR ways. These could change the way how people handle waste management. If logistics activities get easier to use or apply for their 
lifet then reuse, recycle and recover of junk, trash, unused products, used products could work more efficiently (Fleischmann, 2000).

People enjoy easy life. Collecting and separating used products is not an easy act. So, most of them doesn't apply for their life. They consider it as an extra act what doesn't earn what is costs. Because it need much more energy and attention to do this in a proper way. So they just put the whole thing sideway. If would be an easier to do ways they probably use those. There is a possibility for logistics services to improve.

In my thesis I deal with the modelling of transporting at EEE (eletronic- and electrical equipments) products. There is a figure by Imre Dobos who create a modell of recycling in a sealed circle. I represent on the third figure.

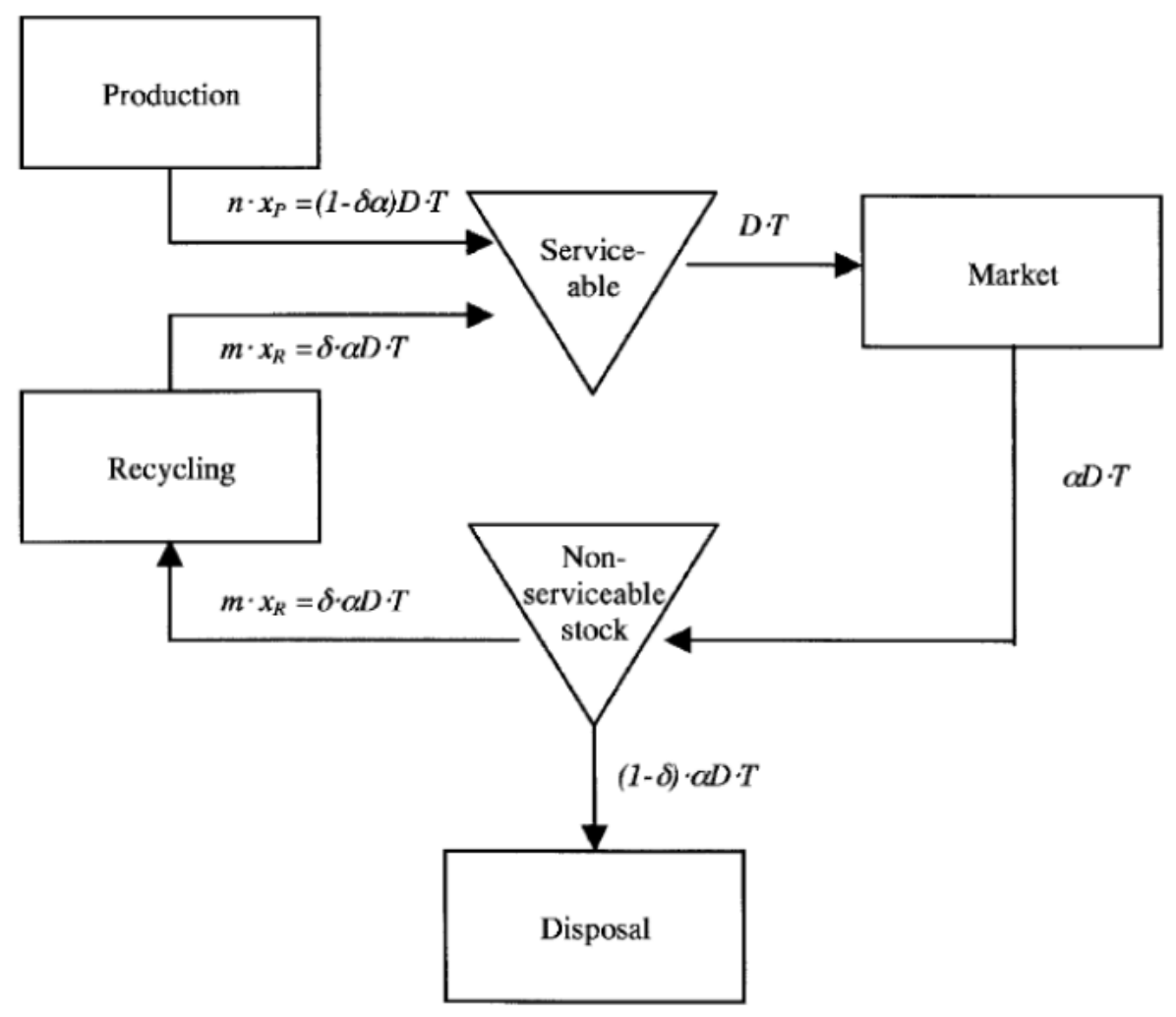

Fig. 3.: The material flow in the model in a production and recycling cycle. source: http://edok.lib.uni-corvinus.hu/27/1/Dobos3.pdf downloaded: april 16., 2015. search engine: google.com, keywords: Dobos, model, Richter

As we can see ont he third figure Dobos (Dobos, 2006) handle the material flow in a sealed way. This means the used materials/products have two options. If it serviceable then get ahead of market. If it not serviceable then it get disposal. It is works in a sealed way because the serviceable parts are get back to the manufaturers. At case of EEE there is another outcome. EEE contains too much components, materials to get back all of them to the original equipment manufacturers to reuse (Rubio, Jiménez-Parra ,2014). At the case of EEE there is a 3rd party unit who get involve. They may prepare used products to reusing or the recycling in another ways. Reusing used product could end in two outcomes. They can create energy by calcination or can create raw materials to other products. 
To reach the goal which is the sustainable waste managemet the transporting, collecting, separating of EEE should be well served. To get well served status reverse logistics could use lean principles.

Lean principles get well known in manufacturing areas. The past goal was to reach a lean or leaner producing or manufacturing method.

Gyenge et al. (2015) conclude, ,that the applicability of Lean is determined by the character of the process and not by the industry. ... The improvement can be successful in any sector although the tools should be adapted to the special features of the industry and the organization, and the thinking methodology described above should be integrated into the organizational culture. To the success and maintenance of Lean transformations there is a need for an organizational culture ready to accept the new approach."

In my opinion other areas of supply chains could apply those principles. Let me present a couple of those.

\section{Results \& Discussion}

The reverse logistics is the las link between consumers and suppliers. So the optimal point of the logistics system depends on he optimal point of reverse logistics system. So the question is how we can apply lean tools in reverse logistics?

It is not an easy task. Let's create a version using ECRS (eleminate, create, rearrange, simplify) tool. We could eleminate the unneseccary transports, duplicity in forwarding, mount of unloaded runs. We could combine the collecting of matching used products, energy retrieval from different products, locations of collector lots. We could rearrange reallocation of made energy, storaging of retrieve materials, reuse of retrived materials. We could simplify recording of communal wastage, transmitting of wastage, tendency of waste management in population.

The other lean tool what I mention is the bottleneck effect. A supply chain could be as wide as the tightest element of its. So bottleneck effect could affect the whole logistics system. If the bottleneck effect shows at reverse logistics then it needs to solve the problem there. First of all we have to identify those spots in the process. What could be these spots? It is hard to define the common ones. Because every other process has different parameters. But I tried to name a few ones. Those might be the vehicles which depends on theris capacity, the capacity of used product shredders, collecting tendency of people, the unintegrated waste management, the deposal of used products, the storaging of retrived energy, the resharing of retrived energy, the rebuild-in of inhomogen materiels to products.

\section{Conclusion}

To conclusion there is a hard way to apply lean tools just for reverse logistics. If we really want to use lean tools efficiently we just have to apply the entire lenght of supply chain because it is the only way to avoid bottleneck effects or system desoptimisations. 


\section{References}

1. Dobos, I., M.: Készletmodellek a visszutas logisztikában. (2006): Budapesti Corvinus Egyetem Gazdálkodástudományi Kar. 73. p. edok.lib.unicorvinus.hu/27/1/Dobos3.pdf Search engine: Google. Keywords: Dobos Imre doktori értekezés. Date of search: 2015. 04.02

2. Fleischmann, M.: Quantitative models for reverse logistics. (2000): 49. p. Search engine: Google repub.eur.nl/pub/1044/EPS-2000-002-LIS+FLEISCHMANN.pdf Keywords: Mannheim University reverse logistics model. Date of search: 2015. 04.08

3. Gyenge B., Szilágyi H., Kozma T. (2015): Lean Management in case of a Logistics Service Provider Company. JOURNAL OF CENTRAL EUROPEAN GREEN INNOVATION

http://greeneconomy.karolyrobert.hu/sites/greeneconomy.foiskola.krf/files/upload/08 Gyenge_et_al_2.pdf III.:(1) pp. 119-134

4. RoHS directive: www.epeat.net/documents/EPEATreferences/EURoHSDirective.pdf Search engine: Google. Keywords: RoHS directive. Date of search: 2015. 04.11

5. Rubio, S., Jiménez-Parra, B.: Reverse logistics: Overview and challenges for supply chain management. (2014): University of Extremadura, School of Industrial Engineering 4. p. Search engine: Google http://cdn.intechopen.com/pdfs-wm/47252.pdf Keywords: reverse logistics supply chain. Date of search: 2015. 04.09

6. Pónusz M. (2013) Reverse Logistics and Sustainability in Hungarian enterprises Logisztikai évkönyv, Budapest. p. 105-110, ISSN: 1218-3849 